\title{
The Moderating Role of Attachment Styles on the Relationship of Alexithymia and Fear of Intimacy with Marital Satisfaction
}

\author{
Mohammad Ali Besharat ${ }^{1}$, Nader Naghshineh ${ }^{1}$, Pooyesh Ganji ${ }^{1} \&$ Fahime Tavalaeyan ${ }^{1}$ \\ ${ }^{1}$ Department of Psychology, University of Tehran, P. O. Box 14155-6456, Tehran, Iran \\ Correspondence: Mohammad Ali Besharat, Department of Psychology, University of Tehran, P. O. Box \\ 14155-6456, Tehran, Iran. E-mail: besharat@ut.ac.ir
}

Received: June 28, 2014

doi:10.5539/ijps.v6n3p106
Accepted: July 21, $2014 \quad$ Online Published: August 24, 2014

URL: http://dx.doi.org/10.5539/ijps.v6n3p106

\begin{abstract}
Attachment styles, alexithymia, and fear of intimacy are considered to be detrimental to degree of satisfaction within the couples relationships. The present study aimed to investigate the moderating role of attachment styles on the relationship of alexithymia and fear of intimacy with marital satisfaction in a sample of Iranian students. Participants (313 males, 375 females) filled the Adult Attachment Inventory (AAI), the Farsi version of the Toronto Alexithymia Scale-20 (FTAS-20), Fear of Intimacy Scale (FIS), and the Golombok Rust Inventory of Marital State Questionnaire (GRIMS). Secure attachment style showed a significant positive association with marital satisfaction, while insecure attachment styles as well as fear of intimacy and alexithymia showed significant negative associations with marital satisfaction. The relationship between fear of intimacy and marital satisfaction was moderated by secure and avoidant attachment styles. The results revealed that only avoidant attachment style could moderate the relationship between alexithymia and marital satisfaction. Results of the present study suggest that the relationship of alexithymia and fear of intimacy with marital satisfaction is not a simple linear one. This is moderated in part by attachment styles. Hence, secure and insecure attachment characteristics may have significant influence in marital relationship in opposite directions.
\end{abstract}

Keywords: attachment, emotion, romantic relationship, marital satisfaction

\section{Introduction}

Marital satisfaction refers to one's general subjective evaluation of his or her marital relationship indicating the degree of satisfaction of one's needs, expectations, and desires in the relationship (Gelles, 1995). Research has indicated that numerous variables have a relationship with marital satisfaction, such as love, commitment, communication, mutual trust, support, fidelity, common interests, mutual understanding, intimacy and mutual exchange of emotions, thoughts, and experiences (e.g., Kaslow \& Robinson, 1996; Litzinger \& Gordon, 2005; Matson, Rogge, Johnson, Davidson, \& Fincham, 2013; Timm \& Kieley, 2011; Waldinger, Schulz, Hauer, \& Allen, 2004). It was showed that values, communication, commitment, emotional intimacy and sexual relationship have the strongest effect on marital satisfaction (Byers, 2005; Henry \& Miller, 2004). Effective communication plays a prominent role in marital satisfaction (Olson \& Olson, 2000; Vangelisti, Reis, \& Fitzpatrick, 2002) and can provide a sense of safety for couples (Stanley, Markman, \& Whitton, 2002).

Quality of communication plays a crucial role in marital satisfaction because it affects marital intimacy (Besharat, 2006; Olson \& Olson, 2000). Negative and destructive communication decreases intimacy and increases the probability of divorce (Stanley et al., 2002). The quantity of communication also discriminates the satisfied and dissatisfied couples. Satisfied couples are more engaged in communication and talk more (Kiecolt-Glaser, Bane, Glaser, \& Malarkey, 2003). Expression of affection is another important factor in recognizing satisfied and dissatisfied couple, because it has an important role in intimacy development (Kathryn \& Timmerman, 2003; Waldinger et al., 2004). Mutual expression of affection leads to more support and self-disclosure among couples (Sanderson \& Evans, 2001). It also predicts the quality of close relationships and marital stability (Gottman, 2001). Empathy affects marital satisfaction because it helps the couples to understand each other better (Kilpatrick, Bissonnette, \& Rusbult, 2002). Waldinger et al. (2004) also indicated happy and well-adjusted couples exhibit more empathy in their relationships. Intimacy development also has a crucial role in marital satisfaction (Besharat, 2003). A study by Olson and Olson (2000) indicated that 96 percent of satisfied couples were comfortable with sharing their emotions and 72 percent of dissatisfied couples thought that their partners 
were not able to understand them. Due to the effects of variables such as intimacy, expression of affection, emotional interaction and empathy on marital satisfaction, the problems and disorders that can affect these variables negatively, can lead to marital dissatisfaction.

Close relationships have a crucial role in people's well-being, psychological health and self-actualization. Thus, recognizing the factors that make these relationships difficult and problematic needs further investigation. Intimacy and emotional interactions are basic elements in achieving marital satisfaction. These characteristics are impaired in people with alexithymia and fear of intimacy. Therefore, one of the objectives of the present study was to investigate the relationship of alexithymia and fear of intimacy with marital satisfaction in a sample of Iranian general population.

Alexithymia is a construct characterized by difficulties in cognitive processing of emotions and regulating them (Taylor \& Bagby, 2000). This multifaceted construct includes difficulty identifying feelings distinguishing between feelings and the bodily sensations of emotional arousal, difficulty communicating feelings to other people, constricted imagination processes and paucity of fantasies and a stimulus-externally oriented cognitive style (Taylor, Bagby, \& Parker, 1997). Along these salient features, other different characteristics such as problems processing emotional information, difficulties in identifying facial expressions, and lower capacity for empathy have been recognized in alexithymic individuals (Vanheule, Desmet, Rossel, Verhaeghe, \& Meganck, 2006). Studies indicate that cold, non-assertive and socially avoidant interpersonal behavior was associated with higher alexithymia scores (Vanheule, Desmet, Verhaeghe, \& Bogarts, 2007). Alexithymics experience various interpersonal problems such as interpersonal indifference, as well as problems in intimacy, sociability, assertiveness, and responsibility (Besharat, 2009). They do not expect much from other people and do not have the desire to fulfill the expectations of others. Alexithymics lack the characteristics necessary for creating and maintaining an intimate relationship and there is a negative relationship between alexithymia and marital satisfaction (Humphreys, Wood, \& Parker, 2009).

Another variable that can affect marital satisfaction is fear of intimacy. Various research on marital satisfaction indicated that intimacy is an effective variable on the satisfaction that a couple experiences (Berman \& Lief, 1975). Fear of intimacy is the limited capacity of a person to share his/her thoughts and emotions with an intimate partner (Descutner \& Thelen, 1991) that results in relationship failure. Fear of intimacy is an effective factor on marital problems and dissatisfaction (Thelen, Vander-Wal, Muir-Thomas, \& Harmon, 2000). Individuals with high scores in fear of intimacy, have difficulty initiating relationship, they do not experience positive feelings about intimate relationships and they have difficulty in self-disclosure. Therefore, they do not feel relational and marital satisfaction (Descutner \& Thelen, 1991). Due to the findings already mentioned, prediction is that alexithymia and fear of intimacy will have a negative relationship with marital satisfaction. However, the main question is whether the relationship between these variables are a simple linear one or other variables might have moderating role between them. Therefore, another objective of the present study was to investigate the moderating role of attachment styles on the relationship of alexithymia and fear of intimacy with marital satisfaction.

Attachment theory (Ainsworth, Blehar, Waters, \& Wall, 1978; Bowlby, 1969), provides a powerful theoretical model for explaining the development of emotions as well as mechanisms of emotion-regulation. Studies show that childhood experiences with caregivers who do not express their emotions, and use insufficient strategies of responding to children's negative emotions, have a strong effect in emotion regulation in adulthood (e.g., Carre're \& Bowie, 2011; Roque \& Veríssimo, 2011). Given the supporting evidence of fundamental influence that child's relationships with attachment figures have on his or her ability to recognize, describe and regulate emotions, the attachment model was considered as a specific theoretical framework in the present study.

Attachment styles are the mental representations of a person's emotional bonds with his or her caregiver in childhood. An individual with secure attachment style "is likely to possess a representational model of attachment figure (s) as being available, responsive, and helpful" (Bowlby, 1980, p. 242). An individual with avoidant attachment style seems very independent of the attachment figure (s) both physically and emotionally (Behrens, Hesse, \& Main, 2007). He/she is likely to have a representational model of attachment figure (s) as being insensitive and rejecting (Ainsworth, 1979). An individual with ambivalent attachment style adopts an ambivalent behavioral style towards the attachment figure(s). He/she is likely to have a representational model of attachment figure as being inconsistent in her availability and responsiveness (Ainsworth, 1979). Attachment styles formed early in life can determine one's pattern of interaction in adulthood (Hazan \& Shaver, 1987). It is found that the infant-mother attachment style can predict the romantic relationship style in adulthood (Hazan \& Shaver, 1987). Research has reported a positive relationship between secure attachment style and marital 
satisfaction, as well as a positive relationship between insecure attachment styles and marital dissatisfaction (Besharat, 2003, 2012; Besharat \& Ganji, 2012).

Research on alexithymia and interpersonal problems (Besharat, 2009; Spitzer, Siebel-Jurges, Barnow, Grabe, \& Freyberger, 2005) indicated that alexithymic individuals are cold and avoidant in their relationships. Research also showed a significant relationship between insecure attachment styles and alexithymia (Besharat, 2010, 2012). It was also showed that alexithymia is more prevalent among individuals with preoccupied and fearful-avoidant attachment styles (Besharat, 2010). Montebarocci and colleagues (2004) found that alexithymia had positive relationship with difficulty initiating relationships, approaching others and it had negative relationship with trusting others (characteristics of insecure attached individuals).

Doi and Thelen (1993) investigated the relationship between fear of intimacy and attachment styles. Fear of intimacy correlated with low levels of intimacy, not trusting others, and fear of rejection (important characteristics of insecure attached individuals). According to Thelen et al. (2000), insecure attachment and fear of intimacy are correlated. Fear of intimacy is characteristic of anxious-ambivalent and avoidant individuals. Anxious-ambivalent attached individuals are conscious about this fear, but avoidant individuals deny the fear because they see themselves as independent and detached.

By mainly examining the moderating role of attachment styles on the relationship of fear of intimacy and alexithymia with marital satisfaction, the following hypotheses were tested in this study: 1) There is a negative relationship between alexithymia and marital satisfaction; 2) There is a negative relationship between fear of intimacy and marital satisfaction; 3) There is a positive relationship between secure attachment style and marital satisfaction; 4) There is a negative relationship between insecure attachment styles and marital satisfaction; 5) Attachment styles have a moderating role on the relationship between alexithymia and marital satisfaction; 6) Attachment styles have a moderating role on the relationship between fear of intimacy and marital satisfaction.

\section{Method}

\subsection{Participants}

A sample of 700 married university students, both male and female, living in Tehran city universities participated in this study, voluntarily. Recruitment conditions consisted of being married within the last five years and having no serious mental or physical disorders that needed medical treatment and no history of divorce at the time of study. Participants were invited to take part in a "study on personality and marital relationships" via announcements made in student dormitories. Participants were asked to complete questionnaires individually. Twelve participants were excluded from statistical analysis because of incomplete responses to the scales, thus the final sample reduced to 688 individuals ( $313 \mathrm{men} ; M_{\text {age }}=31.3$ years, $S D=4.5$, age range: $27-40$ years; 375 women; $M_{\text {age }}=27.8$ years, $\mathrm{SD}=3.9$, age range: $24-36$ years). Mean length of the participants marriage was 3.2 years, $\mathrm{SD}=1.36$, ranged from 1 to 5 years.

\subsection{Procedure}

All participants had to complete the Adult Attachment Inventory (AAI), the Farsi version of the Toronto Alexithymia Scale-20 (FTAS-20), Fear of Intimacy Scale (FIS), and The Golombok Rust Inventory of Marital State Questionnaire (GRIMS). The order of the questionnaires was counterbalanced across participants. To encourage students and increase the accuracy of self-report answering, participants' names and addresses were noted in order to circulate the results of the study. University of Tehran Department of Psychology approved the protocol. All participants signed an informed consent beforehand. All participants were debriefed upon completion and thanked for their participation.

\subsection{Measures}

\subsubsection{Adult Attachment Inventory (AAI)}

The AAI is a 15 -item questionnaire which was derived from the Attachment Style Questionnaire (Hazan \& Shaver, 1987), the Relationship Questionnaire (Bartholomew \& Horowitz, 1991), and the Attachment History Questionnaire (Crowell, Fraley, \& Shaver, 1999) and validated for the purpose of measuring attachment styles in Iranian populations (Besharat, 2005). The AAI consists of three subscales including Secure Attachment Style, Avoidant Attachment Style, and Ambivalent Attachment Style; each of which has 5 items. Each item is rated on a five-point Likert scale ranging from 1 (very little) to 5 (very much). Cronbach's coefficient alpha for the subscales of secure, avoidant and ambivalent was tested in a sample of 1480 participants ( 860 females, 620 males). The Cronbach's alphas for all participants were $.85, .84$, and .85 for secure, avoidant, and ambivalent attachment styles, respectively. These scores were different for women $(.86, .83$, and .84$)$ and men $(.84, .85$ and .86$)$. These scores indicate good internal consistency for the AAI. Test-retest reliability of the AAI was twice calculated in a sample 
of 300 participants at four weeks interval. The coefficients of secure, avoidant, and ambivalent attachment styles for the whole participants were $.87, .83$, and .84 , respectively. These scores were $.86, .82$, and .85 for women, and $.88, .83$ and .83 for men, respectively. All correlation coefficients were significant at $\mathrm{p}<.001$. These scores indicate adequate test-retest reliability of the AAI. Factor analysis identified that secure, avoidant, and ambivalent attachment styles were confirmed by the AAI (Besharat, 2005). In the present study, Cronbach's alpha coefficients were $.88, .85$, and .79 for secure, avoidant, and ambivalent attachment styles, respectively.

\subsubsection{The Farsi version of the Toronto Alexithymia Scale-20 (FTAS-20)}

The FTAS-20 is a Farsi version of The Toronto Alexithymia Scale (TAS-20; Bagby, Parker, \& Taylor, 1994) validated for Iranian populations (Besharat, 2007). The FTAS is a 20 -item self-report measure that provides a total alexithymia score, as well as three sub-scales including Difficulty Identifying Feelings, Difficulty Describing Feelings, and Externally Oriented Thinking. Each item is rated on a five-point Likert scale ranging from 1 (strongly disagree) to 5 (strongly agree). The TAS-20 has demonstrated good psychometric properties (Taylor \& Bagby, 2000; Tolmunen, Heliste, Lehto, Hintikka, Honkalampi et al., 2011). Cronbach's alpha coefficients of the Farsi version of the Toronto Alexithymia Scale-20 (Besharat, 2007) was .85 for the total score, .82 for the difficulty identifying feelings subscale, .75 for the difficulty describing feelings, and .72 for the externally oriented thinking scales. These scores illustrate a significant internal consistency for the FTAS-20. Test-retest reliability of the FTAS-20 was calculated in a sample of 67 participants in two times with a four weeks interval. The test-retest reliability of the FTAS-20 confirmed with coefficients ranged from $r=.70$ to $r=.77(p<.001)$. Confirmatory factor analysis illustrated that, same on the English versions, the existence of three factors was confirmed in the Farsi version as well (Besharat, 2007). In the present study, Cronbach's alpha coefficients were .87, .85, .78 and .73 for alexithymia total score, difficulty identifying feelings, difficulty describing feelings and externally oriented thinking, respectively.

\subsubsection{Fear of Intimacy Scale (FIS)}

The FIS (Descutner \& Thelen, 1991) is a 35-item self-report inventory originally developed to measure anxiety about close dating relationships. The participants are asked to respond to the statements on a 5-point Likert-type scale that ranges from 1 (not at all like me) to 5 (extremely like me). A study done by Descutner and Thelen (1991) indicated that the FIS has high internal consistency (Cronbach's alpha $=.93$ ) and high test-retest reliability $(r=.89)$. Adequate psychometric properties of the FIS have been reported for Iranian populations (Besharat, 2004). The alpha and test-retest reliability coefficients for fear of intimacy total score were .91 and .78, respectively. Cronbach's alpha coefficient for fear of intimacy total score was .89 for the present study.

\subsubsection{The Golombok Rust Inventory of Marital State Questionnaire (GRIMS)}

The GRIMS (Rust, Bennun, Crow, \& Golombok, 1986) is a 28 -item self-report questionnaire that has been developed for the assessment of marital problems within the couple's relationship. Each item is rated on a 4-point Likert-type scale that ranges from 0 (strongly agree) to 3 (strongly disagree). The GRIMS has demonstrated good psychometric properties (Rust et al., 1986). Alpha coefficients of a Farsi version of the GRIMS total score were .91 and .88 for a sample of Iranian husbands and wives, respectively (Besharat, 2003). Test-retest reliability of the GRIMS confirmed with coefficients of .73 and .81 for a sample of 74 husbands and wives, respectively (Besharat, 2003). Cronbach's alpha coefficient for the GRIMS total score was .88 for the present study.

\section{Results}

Table 1 shows the statistical characteristics of participants according to attachment styles, alexithymia, fear of intimacy, and marital satisfaction. Means and standard deviations for all study variables revealed no significant differences between men and women in secure attachment $\left(t_{686}=4.80, p=.42\right)$, avoidant attachment $\left(t_{686}=1.67\right.$, $p=.96)$, ambivalent attachment $\left(t_{686}=2.88, p=.47\right)$, and alexithymia $\left(t_{686}=7.62, p=.17\right)$. However, they were significantly different in fear of intimacy $\left(t_{686}=.881, p=.037\right)$ and marital satisfaction $\left(t_{686}=5.02, p=.047\right)$; women scored higher in fear of intimacy scale and lower in marital satisfaction measure than men. Table 1 also presents zero order correlations between attachment styles, alexithymia, fear of intimacy, and marital satisfaction for each gender. For both men and women, there were significant correlations between attachment styles, alexithymia, fear of intimacy, and marital satisfaction. These findings confirm the first four hypotheses of the study. As the pattern of correlations between variables was relatively similar for the two groups of men and women, subsequent analyses were collapsed across gender. 
Table 1. Mean scores, standard deviations, and zero order correlations between study variables

\begin{tabular}{llllllllllll}
\hline & \multicolumn{7}{c}{ Women(n=375)\Men( $\mathrm{n}=313) \dagger$} \\
\hline Variable & $\mathrm{M}(\mathrm{SD})$ & 1 & 2 & 3 & 4 & 5 & 6 & 7 & 8 & 9 \\
1. Secure Attachment & $15.56(3.16)$ & 1 & -.64 & -.31 & -.22 & -.17 & -.21 & $\mathrm{NS}$ & -.35 & .54 \\
2. Avoidant Attachment & $12.62(3.50)$ & -.66 & 1 & .37 & .18 & .21 & .30 & $\mathrm{NS}$ & .33 & -.58 \\
3. Ambivalent Attachment & $11.05(3.24)$ & -.34 & .53 & 1 & .24 & .25 & .18 & $\mathrm{NS}$ & .31 & -.42 \\
4. Alexithymia & $48.98(10.17)$ & -.21 & .16 & .25 & 1 & .80 & .78 & .66 & .56 & -.45 \\
5. DIF & $16.94(5.57)$ & -.18 & .18 & .32 & .88 & 1 & .49 & .33 & .44 & -.37 \\
6. DDF & $12.91(3.81)$ & -.22 & .17 & .17 & .81 & .60 & 1 & .43 & .48 & -.36 \\
7. EOT & $19.12(3.59)$ & $\mathrm{NS}$ & $\mathrm{NS}$ & $\mathrm{NS}$ & .68 & .36 & .37 & 1 & .28 & -.25 \\
8. Fear of intimacy & $70.36(19.95)$ & -.27 & .26 & .28 & .58 & .53 & .51 & .32 & 1 & -.56 \\
9. Marital satisfaction & $55.93(10.02)$ & .41 & -.44 & -.43 & -.49 & -.46 & -.45 & -.26 & -.53 & 1 \\
\hline
\end{tabular}

$\dagger$ Top right of table represents correlations for men and the bottom left of the table represents the correlations for women; $\mathrm{M}=$ Mean; SD = Standard Deviation; DIF = Difficulty Identifying Feelings; DDF = Difficulty Describing Feelings; EOT = Externally Oriented Thinking; NS = Not significant

Note. All $p$ values $<.001$

A series of multiple regression analyses were conducted in order to examine the moderating effect of attachment styles on the relationship between alexithymia and marital satisfaction. The results of these analyses are shown in Table 2. These results revealed that with entering attachment styles as moderating variables in regression equation, $\mathrm{R}^{2}$ increased from .33 to .34 at a significant level $\left(\Delta \mathrm{R}^{2}=.01, \Delta \mathrm{F}=5.43, p=.020\right)$ only for avoidant attachment style, indicating that avoidant attachment style could moderate the relationship between alexithymia and marital satisfaction.

Table 2. Standardized and unstandardized coefficients for moderating effect of avoidant attachment style on the relationship between alexithymia and marital satisfaction

\begin{tabular}{llllll}
\hline Model 1 & B & SE B & $\beta$ & $t$ & $p$ \\
\hline Alexithymia & -.328 & .034 & -.302 & -9.630 & .001 \\
Avoidant attachment style & -1.431 & .099 & -.454 & -14.486 & .001 \\
Model 2 & & & & & \\
Alexithymia & -.049 & .124 & -.045 & -.392 & .695 \\
Avoidant attachment style & -1.402 & .099 & -.445 & -14.124 & .001 \\
Avoidant attachment style $\times$ Alexithymia & -.223 & .096 & -.268 & -2.330 & .020
\end{tabular}

Model 1: Predictive variables: alexithymia and avoidant attachment style

Model 2: Predictive variables: alexithymia, avoidant attachment style, and moderating effect of avoidant attachment style

A series of multiple regression analyses were conducted in order to examine the moderating effect of attachment styles on the relationship between fear of intimacy and marital satisfaction. The results of these analyses are shown in Table 3. These results revealed that with entering attachment styles in regression equation as moderating variables, $\mathrm{R}^{2}$ increased from .41 to .42 at a significant level $\left(\Delta \mathrm{R}^{2}=.01, \Delta \mathrm{F}=5.73, p=.017\right)$ for secure attachment style indicating that secure attachment style could moderate the relationship between fear of intimacy and marital satisfaction. 
Table 3. Standardized and unstandardized coefficients for moderating effect of secure attachment style on the relationship between fear of intimacy and marital satisfaction

\begin{tabular}{llllll}
\hline Model 1 & B & SE B & $\beta$ & $t$ & $p$ \\
\hline Fear of intimacy & -.255 & .017 & -.463 & -15.124 & .001 \\
Secure attachment style & -.145 & .107 & .328 & 10.725 & .001 \\
Model 2 & & & & & \\
Fear of intimacy & -.436 & .077 & -.791 & -5.633 & .001 \\
Secure attachment style & 1.070 & .111 & .307 & 9.655 & .001 \\
Secure attachment style $\times$ Fear of intimacy & .237 & .099 & .330 & 2.394 & .017 \\
\hline
\end{tabular}

Model 1: Predictive variables: fear of intimacy and secure attachment style

Model 2: Predictive variables: fear of intimacy, secure attachment style, and moderating effect of secure attachment style

Similar analyses revealed that when avoidant attachment style entered in regression equation as moderating variable, $\mathrm{R}^{2}$ increased from .44 to .46 at a significant level $\left(\Delta \mathrm{R}^{2}=.02, \Delta \mathrm{F}=11.11, p=.001\right)$ indicating that avoidant attachment style could moderate the relationship between fear of intimacy and marital satisfaction (See Table 4).

Table 4. Standardized and unstandardized coefficients for moderating effect of avoidant attachment style on the relationship between fear of intimacy and marital satisfaction

\begin{tabular}{llllll}
\hline Model 1 & B & SE B & $\beta$ & $t$ & $p$ \\
\hline Fear of intimacy & -.252 & .017 & -.457 & -15.265 & .001 \\
Avoidant attachment style & -1.138 & .094 & -.361 & -12.074 & .001 \\
Model 2 & & & & & \\
Fear of intimacy & -.073 & .056 & -.132 & -1.296 & .196 \\
Avoidant attachment style & -1.078 & .095 & -.342 & -11.302 & .001 \\
Avoidant attachment style $\times$ Fear of intimacy & -.268 & .080 & -.344 & -3.334 & .001 \\
\hline
\end{tabular}

Model 1: Predictive variables: fear of intimacy and avoidant attachment style

Model 2: Predictive variables: fear of intimacy, avoidant attachment style, and moderating effect of avoidant attachment style

\section{Discussion}

The present study examined the moderating role of attachment styles on the relationship of alexithymia and fear of intimacy with marital satisfaction. Results of the present study indicated that alexithymia, fear of intimacy, avoidant attachment style, and ambivalent attachment style had significant negative correlations with marital satisfaction, while secure attachment style showed a significant positive correlation with marital satisfaction. These results are consistent with previous findings (Besharat, 2003, 2009, 2012; Besharat \& Ganji, 2012; Mikulincer \& Shaver, 2007; Montebarocci et al., 2004) and explained in terms of several possibilities.

Previous studies indicated that individuals with alexithymia have difficulty identifying facial expressions of emotions (Parker et al., 1993). Being able to correctly identify emotions is a crucial factor in interpersonal relationships. Difficulty identifying emotions leads to various interpersonal problems in couples and decreases marital satisfaction. Inability to recognize emotions undermines the development of intimacy within the couples' relationships. Therefore, it can be concluded that alexithymia may decrease marital satisfaction through difficulty identifying emotions. This finding confirms the possible psychopathological influence of alexithymia and gives support to the theoretical conceptualizations and research findings of alexithymia.

Difficulty regulating emotions is one of the characteristics of alexithymic individuals (Taylor \& Bagby, 2000). This deficiency at the same time results in psychological distress producing problems at both personal and 
interpersonal levels. Having difficulty regulating emotions, individuals become vulnerable to interpretation of daily life realities. Moreover, difficulty regulating emotions makes emotional information processing which is crucial in the context of couples relationships damaged (Besharat, 2009, 2012; Besharat \& Ganji, 2012; Culhane \& Watson, 2003; Saarijavi, Salminen, \& Toikka, 2001). These emotional and cognitive deficiencies may decrease marital satisfaction either through impaired recognition of what is happening for oneself and also within a close relationship or using ineffective coping strategies.

Fear of intimacy by limiting the capacity and ability of the individual to become related with others, especially in the area of emotions (Descutner \& Thelen, 1991), is one of the prominent factors in marital dissatisfaction (Thelen et al, 2000). Couples with fear of intimacy are always worried about the activation of emotional conflicts around intimacy, thus are not able to express their emotions. Expression of emotion as a basic factor in intimacy development (Kathryn \& Timmerman, 2003; Waldinger et al., 2004) is one of the indicators of marital satisfaction. Mutual expression of emotion can also create safety and support for couples and increase self-disclosure (Sanderson \& Evans, 2001). Research has indicated that self-disclosure has positive relationship with marital satisfaction (Lippert \& Prager, 2001). Therefore, one can explain that fear of intimacy produces marital dissatisfaction for couples through impaired self-disclosure. The relationship between fear of intimacy and marital satisfaction can also be explained by the empathic ability of one to share another person's feelings. Intimacy strengthens emotional skills and emotion expression ability (Cordova, Gee, \& Warren, 2005). Empathy as one of these abilities helps the couples to share their feelings and improve their understanding which in turn increases marital satisfaction (Cordova et al., 2005; Kilpatrick et al., 2002; Wilkie, Ferree, \& Ratcliff, 1998). Conversely, fear of intimacy by weakening the emotional abilities such as empathy, decreases marital satisfaction.

Secure internal working models are created in the framework of attachment relationship between mother and infant and by establishment of schemas and basic positive attitudes toward mother (and then others), create intrapersonal and interpersonal contexts for establishing intimate relationship with others (Bowlby, 1969, 1980; Hazan \& Shaver, 1987). Secure internal working models in intrapersonal dimension, create an image of a self who deserves support and love and in interpersonal dimension, create an image of others as supportive and kind for the secure individual. Images in both intrapersonal and interpersonal dimensions prepare the secure attached individual for initiating and maintaining intimate relationships. In addition, these dimensions, by having mutual interaction, reinforce each other and strengthen the ability of the individual for exchanging intimacy. On the contrary, insecure working models by establishing schemas and basic negative feedback about mother (then others), in the intrapersonal dimension, create an image of the self with no deserve for support and love, and in interpersonal dimension, create an image of others who are rejecting and unkind. These two dimensions of insecurity and inadequacy weaken the abilities of the individual to create intimate relationships and increase their fear of intimacy. Mutual interactions of these dimensions, which negatively strengthen each other, increase the individual's fear of intimacy (Besharat \& Firoozi, 2006). These explanations are served as justification for a) the positive and negative relationship of secure and insecure attachment styles with marital satisfaction and dissatisfaction, and b) the positive and negative relationship of fear of intimacy with dissatisfaction and satisfaction in intimate relationships. These findings lend support to attachment theory (Ainsworth et al., 1978; Bowlby, 1969) and are consistent with existing evidence of a robust relationship between early attachment experiences and emotion-regulation abilities later on (e.g., Carre're \& Bowie, 2011; Roque \& Veríssimo, 2011).

Results of the present study revealed that avoidant attachment style moderated the relationship of alexithymia and fear of intimacy with marital satisfaction, while secure attachment style only moderated the relationship between fear of intimacy and marital satisfaction. These results are consistent with previous findings (Besharat, 2003, 2009, 2012; Besharat \& Ganji, 2012; Mikulincer \& Shaver, 2007; Montebarocci et al., 2004) and are explained in terms of several possibilities.

Emotion regulation strategies are influenced by attachment styles (Bowlby, 1969). Parents of secured attached individuals are described as responsive and sensitive to their children. Therefore, these individuals have learned how to regulate their emotions and interact with other people (Bowlby, 1969). Individuals with better emotion regulation skills can have better functioning in their intimate relationships, thus they can experience greater satisfaction in their relationships. Alexithymia is a disorder of disability in emotion regulation. Emotional development and cognitive skills of emotion regulation are impaired in these individuals (Taylor \& Bagby, 2000). Due to the effect of attachment on emotion regulation, alexithymic individuals with more insecurity, are less able to regulate their emotions and as a result, feel less satisfaction in their intimate relations. Individuals with avoidant attachment style are not able to trust others, thus they tend to keep physical, emotional and cognitive distance from others and do not feel that they are mutually attached to others (Bartholomew \& 
Horowitz, 1991). Alexithymic individuals have poor social networks, various interpersonal problems and they are not eager to approach others (Besharat, 2009; Montebarocci et al., 2004). Intimacy avoidance and keeping distance from others is a prominent factor in producing dissatisfaction in relationships. Therefore, more the alexithymic individual is insecure, more he/she is reluctant to approach others and become intimate. As a result, avoidant attachment style can increase the negative effects of alexithymia on marital satisfaction.

Avoidant attached individuals do not expect others' help and support, as they do not tend to help others, when they are distressed. They care less about understanding other's feelings. They are not able to empathize and sympathize with others. Difficulty empathizing with others is a prominent feature of alexithymia. They also are not willing to satisfy other's needs and demands. Empathy is a determinant factor in relational satisfaction (Wilkie et al., 1998). Therefore, insecure attachment decreases marital satisfaction through undermining empathy.

Expression of emotion is an important factor in marital satisfaction (Kathryn \& Timmerman, 2003; Waldinger et al, 2004). Mutual expression of emotion provides a safe atmosphere and increases self-disclosure. Avoidant attached individuals are so cold in their relationships and are not able to create intimacy (Kathryn \& Timmerman, 2003). One of the factors that create intimacy in the relationship is self-disclosure (Sanderson \& Evans, 2001). Difficulty expressing emotions and understanding other's emotions is a feature of alexithymia. Insecure attachment style can affect this aspect negatively, producing marital dissatisfaction.

With regard to the moderating role of secure and avoidant attachment styles on the relationship between fear of intimacy and marital satisfaction, one of the elements of intimacy is disclosing and expressing emotions and thoughts. Insecurity of attachment results in inability of the individual in exchanging beliefs, thoughts and emotions with others (Timmerman, 1991). Therefore, insecure attachment style can strengthen the negative effects of fear of intimacy on marital dissatisfaction, while secure attachment style decrease the negative effects of fear of intimacy on marital dissatisfaction.

Positive attitudes toward others and trust in self and others are basic characteristics of secure attachment style, and negative attitudes toward others and distrusting self and others are basic characteristics of avoidant attachment style (Ainsworth et al., 1978; Bartholomew \& Horowitz, 1991). These characteristics, which are known as positive and negative working models, produce the context of satisfaction and dissatisfaction in interpersonal relationships. On this basis, secure attachment style with positive attitude and trust in self and others, decrease the relationship between fear of intimacy and marital dissatisfaction. Avoidant attachment style with negative attitude and distrust in self and others increases the relationship between fear of intimacy and marital dissatisfaction. In other words, avoidance of intimacy and avoiding others that are the characteristics of avoidant attached individuals, are prominent factors in marital dissatisfaction. Insecure individuals are less eager to approach others and experience intimacy in their relationships. Thus, avoidant attachment can intensify the negative effects of fear of intimacy on marital dissatisfaction.

\subsection{Limitations}

The present study has several limitations. First, the present study was cross-sectional and utilized self-report measures. Although this study provides evidence for the moderating role of attachment styles on the relationship of alexithymia and fear of intimacy with marital satisfaction, the cross-sectional design prevents an understanding of the exact nature of the relationships, particularly with respect to directionality. Longitudinal studies may further explain the importance of attachment and emotional characteristics in marital satisfaction. Self-report measures are also vulnerable to subjective biases and heavily influenced by forces of social desirability and self-presentation. Consequently, it is important that future studies employ different measures in order to get more reliable findings concerning the research variables. Second, the present study focused on moderating role of attachment styles. Consequently, it is important that future studies employ different variables which may have potential to play a moderating role, in order to lead to a better understanding of the role of emotional, cognitive, and personality factors in the development and perpetuation of marital satisfaction. Also for better understanding the disrupting effects of alexithymia and fear of intimacy, as well as attachment related disorders on marital dissatisfaction, it is suggested to study these relationships in clinical samples including individuals with psychological disorders, personality disorders and samples with familial and interpersonal problems. Finally, it must be pointed out that predictive variables tested in the present study might have different effects through their interactions with some clinical, demographic, and sociocultural factors that had not chance to be evaluated. For example, students who participated in the present study were at early stage of their marriages. Future research needs to address this issue. 


\subsection{Implications}

Based on the results of the present study, one can conclude that emotional foundations of personal development might function as a contributing factor for marital satisfaction or dissatisfaction. This is in line with the previous findings that have provided evidence in support of attachment theory assumptions (Ainsworth et al., 1978; Bowlby, 1969), the importance of emotion-regulation abilities (Kreitler, 2002; Sifneos, 2000), and basic elements of good communication including empathy and self-disclosure (Besharat, 2006). Results of the present study can also produce an empirical basis for designing educational and health programs for interpersonal relationships; programs for intervening and managing emotions; and programs by the aim of strengthening the intimate relationship of couples. The predictive variables investigated in the present study, more specifically attachment styles, may be of potential interest for couple and family therapists. Accordingly, the proper assessment of attachment styles, alexithymia, and fear of intimacy in clinical settings may provide invaluable information for intervention and management programs. Clinicians should consider working with couples to reduce their insecure characteristics. These efforts might involve attempts to identify and alter emotional dysregulations, difficulties of identifying and describing feelings, and problems with expression of emotions as well as self-disclosure in order to increase marital satisfaction. These programs might also help the existing attachment based and emotional oriented intervention models.

\section{Acknowledgments}

The authors would like to acknowledge the financial support of University of Tehran for this research under grant number 5106003/1/58

\section{References}

Ainsworth, M. D. S. (1979). Infant-mother attachment. American Psychologist, 34, 932-937. http://dx.doi.org/10.1037/0003-066X.34.10.932

Ainsworth, M. D. S., Blehar, M. C., Waters, E., \& Wall, S. (1978). Patterns of attachment: A psychological study of the strange situation. Hillsdale, NJ: Erlbaum.

Bagby, R. M., Parker, J. D. A., \& Taylor, G. J. (1994). The twenty-item Toronto Alexithymia Scale: Item selection and cross-validation of the factor structure. Journal of Psychosomatic Research, 38, 23-32. http://dx.doi.org/10.1016/0022-3999(94)90005-1

Bartholomew, K., \& Horowitz., L. M. (1991). Attachment styles among young adults: A test of four-category model. Journal of Personality and Social Psychology, 61, 226-244. $\mathrm{http}: / / \mathrm{dx}$.doi.org/10.1037/0022-3514.61.2.226

Behrens, K. Y., Hesse, E., \& Main, M. (2007). Mothers' attachment status as determined by the Adult Attachment Interview predicts their 6-year-olds' reunion responses: A study conducted in Japan. Developmental Psychology, 43, 1553-1567. http://dx.doi.org/10.1037/0012-1649.43.6.1553

Besharat, M. A. (2003). Relation of attachment style with marital conflict. Psychological Reports, 92, 1135-1140. http://dx.doi.org/10.2466/pr0.2003.92.3c.1135

Besharat, M. A. (2004). Reliability and factorial validity of Farsi version of the Fear of Intimacy Scale with a sample of Iranian populations. Unpublished research report. Tehran: University of Tehran. [Farsi]

Besharat, M. A. (2005). Development and validation of the Adult Attachment Inventory. Unpublished research report. Tehran: University of Tehran. [Farsi]

Besharat, M. A. (2006). What are the elements of good communication within a couple relationship? Journal of Psychological Science, 16, 5-25. [Farsi]

Besharat, M. A. (2007). Reliability and factorial validity of Farsi version of the Toronto Alexithymia Scale with a sample of Iranian students. Psychological Reports, 101, 209-220.

Besharat, M. A. (2009). Alexithymia and interpersonal problems. Studies in Education \& Psychology, 1, 129-145. [Farsi]

Besharat, M. A. (2010). Attachment styles and alexithymia. Psychological Research, 24, 63-80. [Farsi]

Besharat, M. A. (2012). The relationship between fear of intimacy and marital satisfaction in a sample of Iranian couples: Moderating role of attachment styles. Applied Counseling, 2, 1-18. [Farsi]

Besharat, M. A., \& Firoozi, M. (2006). Attachment styles and fear of intimacy. Journal of Psychological Science, 17, 5-15. [Farsi] 
Besharat, M. A., \& Ganji, P. (2012). The moderating role of attachment styles on the relationship of alexithymia with marital satisfaction. The Journal of Fundamentals of Mental Health, 55, 324-335. [Farsi]

Berman, E. M., \& Lief, H. L. (1975). Marital therapy from a psychiatric perspective: An overview. American Journal of Psychiatry, 132, 583-592.

Bowlby, J. (1969). Attachment and loss: Vol. I. Attachment. New York: Basic Books.

Bowlby, J. (1980). Attachment and loss: sadness and depression. New York: Basic Books.

Byers, E. S. (2005). Relationship satisfaction and sexual satisfaction: A longitudinal study of individuals in long-term relationships. Journal of Sex Research, 42, 113-118. http://dx.doi.org/10.1080/00224490509552264

Carrère, S., \& Bowie, B. H. (2012). Like parent, like child: Parent and child emotion dysregulation. Archives of Psychiatric Nursing, 26, 23-30. http://dx.doi.org/10.1016/j.apnu.2011.12.008

Cordova, J. V., Gee, C. B., \& Warren, L. Z. (2005). Emotional skillfulness in marriage: Intimacy as a mediator of the relationship between emotional skillfulness and marital satisfaction. Journal of Social and Clinical Psychology, 24, 218-235. http://dx.doi.org/10.1521/jscp.24.2.218.62270

Crowell, J. A., Fraley, R. C., \& Shaver, P. R. (1999). Measurement of individual differences in adolescents and adult attachment. In J. Cassidy, \& P. R. Shaver (Eds.), Handbook of Attachment: Theory, research, and clinical applications (pp. 434-465). New York, NY, US: Guilford Press.

Culhane, S. E., \& Watson, P. J. (2003). Alexithymia, irrational beliefs, and the rationale motive explanation of emotional disturbance. Journal of Rational-Emotive and Cognitive-Behavior Therapy, 21, 57-72.

Descutner, C. J., \& Thelen, M. H. (1991). Development and validation of a Fear-of-Intimacy Scale. Journal of Counseling and Clinical Psychology, 3, 218-225.

Doi, S., \& Thelen, M. (1993). The Fear-of-Intimacy Scale: Replication and extension. Psychological Assessment, 5, 377-383. http://dx.doi.org/10.1037/1040-3590.5.3.377

Feeney, J. A. (1996). Attachment, caregiving, and marital satisfaction. Personal Relationships, 3, 401-416. http://dx.doi.org/10.1111/j.1475-6811.1996.tb00124.x

Gelles, R. J. (1995). Contemporary families: A sociological view. Thousand Oaks: Sage

Gottman, J. M. (2001). What the study of relationships has to say about emotion research. Social Science Information, 40, 79-94. http://dx.doi.org/10.1177/053901801040001005

Hazan, C., \& Shaver, P. R. (1987). Romantic Love conceptualized as an attachment process. Journal of Personality and Social Psychology, 52, 511-524. http://dx.doi.org/10.1037/0022-3514.52.3.511

Henry, R. G., \& Miller, R. B. (2004). Marital problems occurring in midlife: Implications for couple's therapy. American Journal of Family Therapy, 32, 405-417. http://dx.doi.org/10.1080/01926180490455204

Humphreys, T. P., Wood, L. M., \& Parker, J. D. A. (2009). Alexithymia and satisfaction in intimate relationships. Personality and Individual Differences, 46, 43-47. http://dx.doi.org/10.1016/j.paid.2008.09.002

Kaslow, F., \& Robinson, J. A. (1996). Long-term satisfying marriages: Perceptions of contributing factors. American Journal of Family Therapy, 24, 153-170. http://dx.doi.org/10.1080/01926189608251028

Kathryn, D., \& Timmerman, L. (2003). Accomplishing romantic relationship. In J. O. Greene, \& B. R. Burleson (Eds.), Handbook of communication and social interaction skills (pp. 685-90). Mahwah: Lawrence Erlbaum Associates.

Kiecolt-Glaser, J. K., Bane, C., Glaser, R., \& Malarkey, W. B. (2003). Love, marriage, and divorce: Kathryn, D., \& Timmerman, L. (2003). Accomplishing romantic relationship. In J. O. Greene, \& B. R. Burleson (Eds.), Handbook of communication and social interaction skills (pp. 685-690). Mahwah: Lawrence Erlbaum Associates.

Kilpatrick, S. D., Bissonnette, V. L., \& Rusbult, C. R. (2002). Empathic accuracy and accommodative behavior among newly married couples. Personal Relationships, 9, 369-393. http://dx.doi.org/10.1111/1475-6811.09402

Kreitler, S. (2002). The psychosemantic approach to alexithymia. Personality and Individual Differences, 33, 393-407. http://dx.doi.org/10.1016/S0191-8869(01)00163-5

Krystal, H. (1979). Alexithymia and psychotherapy. American Journal of Psychotherapy, 33, 17-31. 
Lippert, T., \& Prager, K. J. (2001). Daily experiences of intimacy: A study of couples. Personal Relationships, 8, 283-298. http://dx.doi.org/10.1111/j.1475-6811.2001.tb00041.x

Litzinger, S., \& Gordon, K. C. (2005). Exploring relationships among communication, sexual satisfaction, and marital satisfaction. Journal of Sex and Marital Therapy, 31, 409-424. http://dx.doi.org/10.1080/00926230591006719

Matson, R. E., Rogge, R. D., Johnson, M. D., Davidson, E. K. B., \& Fincham, F. D. (2013). The positive and negative semantic dimensions of relationship satisfaction. Personal Relationships, 20, 328-355. http://dx.doi.org/10.1111/j.1475-6811.2012.01412.x

McDougall, J. (1989). Theatres of the body: a psychoanalytic approach to psychosomatic illness. New York: Norton.

Mikulincer, M. \& Shaver, P. (2007). Attachment in adulthood: Structure, dynamics and change. New York: The Guilford Press.

Montebarocci, O., Codispoti, M., Baldaro, B., \& Rossi, N. (2004). Adult attachment style and alexithymia. Personality and Individual Differences, 36, 499-507. http://dx.doi.org/10.1016/S0191-8869(03)00110-7

Olson, D. H., \& Olson, A. K. (2000). Empowering couples: Building on your strengths. Minneapolis: Life Innovations.

Parker, J. D. A., Taylor, G. J., \& Bagby, R. M. (1993). Alexithymia and the processing of emotional stimuli: An experimental study. New Trends in Experimental and Clinical Psychiatry, 9, 9-14.

Roque, L., \& Veríssimo, M. (2011). Emotional context, maternal behavior and emotion regulation. Infant Behavior and Development, 34, 617-626. http://dx.doi.org/10.1016/j.infbeh.2011.06.002

Rust, J., Bennun, I., Crow, M., \& Golombok, S. (1986). The Golombok-Rust Inventory of Marital State Questionnaire. Sexual and Marital Therapy, 1, 55-60. http://dx.doi.org/10.1080/02674658608407680

Saarijarvi, S., Salminen, J. K., \& Toikka, T. B. (2001). Alexithymia and depression: A one year follow-up study in out patients with major depression. Journal of Psychosomatic Research, 51, 729-733. http://dx.doi.org/10.1016/S0022-3999(01)00257-4

Sanderson, C. A., \& Evans, S. M. (2001). Seeing one's partner through intimacy-colored glasses: An examination of the process underlying the intimacy goals-relationship satisfaction link. Personality \& Social Psychology Bulletin, 27, 463-473. http://dx.doi.org/10.1177/0146167201274007

Sifneos, P. E. (2000). Alexithymia, clinical issues, politics and crime. Psychotherapy and Psychosomatics, 69, 113-116. http://dx.doi.org/10.1159/000012377

Spitzer, C., Siebel-Jürges, U., Barnow, S., Grabe, H., \& Freyberger, H. (2005). Alexithymia and interpersonal problems. Psychotherapy and Psychosomatics, 74, 240-246. http://dx.doi.org/10.1159/000085148

Stanley, S. M., Markman, H. J., \& Whitton, S. W. (2002). Communication, conflict, and commitment: Insights on the foundations of relationship success from a national survey. Family Process, 41, 659-675. http://dx.doi.org/10.1111/j.1545-5300.2002.00659.x

Taylor, G. J., \& Bagby, M. (2000). An overview of the alexithymia construct. In R. Bar-On, \& J. D. A. Parker (Eds.), The handbook of emotional intelligence (pp. 263-276). San Francisco: Jossey-Bass.

Taylor, G. J., Bagby, M., \& Parker, J. D. A. (1997). Disorders of affect regulation: Alexithymia in medical and psychiatric illness. Cambridge: Cambridge University Press. http://dx.doi.org/10.1017/CBO9780511526831

Thelen, M. H., Vander-Wal, J. S., Muir-Thomas, A., \& Harmon, R. (2000). Fear of intimacy among dating couples. Behavior Modification, 24, 223-240. http://dx.doi.org/10.1177/0145445500242004

Tolmunen, T., Heliste, M., Lehto, S. M., Hintikka, J., Honkalampi, K., \& Kauhanen, J. (2011). Stability of alexithymia in the general population: An 11-year follow-up. Comprehensive Psychiatry, 52, 536-541. http://dx.doi.org/10.1016/j.comppsych.2010.09.007

Timm, T. M., \& Keiley, M. K. (2011). The effects of differentiation of self, adult attachment, and sexual communication on sexual and marital satisfaction: A path analysis. Journal of Sex and Marital Therapy, 37, 206-223. http://dx.doi.org/10.1080/0092623X.2011.564513

Timmerman, G.M. (1991). A concept analysis of intimacy. Issues in Mental Health Nursing, 12, 19-30. http://dx.doi.org/10.3109/01612849109058207 
Vangelisti, A. L., Reis, H. T., \& Fitzpatrick, M. A. (2002). Stability and change in relationships. Cambridge: Cambridge University Press. http://dx.doi.org/10.1017/CBO9780511499876

Vanheule, S., Desmet, M., Meganck, R., \& Bogaerts, S. (2007). Alexithymia and interpersonal problems. Journal of Clinical Psychology, 63, 109-117. http://dx.doi.org/10.1002/jclp.20324

Vanheule, S., Desmet, M., Rosseel, Y., Verhaeghe, P., \& Meganck, R. (2006). Relationship patterns in Alexithymia: A study using the core conflictual relationship theme method. Psychopathology, 40, 14-21. http://dx.doi.org/10.1159/000096385

Waldinger, R. J., Schulz, M. S., Hauer, S. T., \& Allen, J. P. (2004). Reading others' emotions: The role of intuitive judgments in predicting marital satisfaction, quality, and stability. Journal of Family Psychology, 18, 58-71. http://dx.doi.org/10.1037/0893-3200.18.1.58

Wilkie, J. R., Ferree, M. M., \& Ratcliff, K. S. (1998). Gender and fairness: Marital satisfaction in two-earner couples. Journal of Marriage and the Family, 60, 577-594. http://dx.doi.org/10.2307/353530

\section{Copyrights}

Copyright for this article is retained by the author(s), with first publication rights granted to the journal.

This is an open-access article distributed under the terms and conditions of the Creative Commons Attribution license (http://creativecommons.org/licenses/by/3.0/). 